\title{
Leading Digital Transformation: The Scandinavian Way
}

\author{
Bendik Bygstad ${ }^{1,2}$, Hans-Petter Aanby ${ }^{3}$ and Jon Iden ${ }^{2}$ \\ ${ }^{1}$ University of Oslo, University of Oslo, Gaustadalléen 23, 0373 Oslo, Norway, \\ bendikby@ifi.uio.no \\ ${ }^{2} \mathrm{NHH}$ Norwegian School of Economics, Bergen, Helleveien 30, 5045 Bergen, Norway, \\ jon.iden@nhh.no \\ ${ }^{3}$ OptimiseIT AS, hans-petter@optimiseit.no
}

\begin{abstract}
Digital transformation can be seen as the mutual reinforcement of process redesign and innovative use of IT. The literature on digital transformation focuses on digital business strategy and the transformational CIO. Stakeholder engagement in combination with leadership style is seldom discussed. Our research questions are (i) what characterises leadership in the digital transformation, and (ii) what does the Scandinavian workplace model add to the knowledge of digital transformation? Our empirical evidence is the digital transformation in a large airline, the SAS, during the years 2013-16. The process was very turbulent but eventually quite successful. We identify two Scandinavian contributions to transformation research: firstly, the deep engagement with employees, including trade unions, supports a structured process with a focus on finding solutions, not conflicts. Second, a coaching leadership style, allowing space for autonomy, leverages the competence of highlyskilled employees.
\end{abstract}

Keywords: digital transformation, transformational leadership, Scandinavian workplace model, CIO, case study

\section{Introduction}

It is one of the hard facts of management research that most managers do not get much done during their tenure, except keeping up with daily tasks and problems. This applies also to CIOs; many of them dream and talk about digital transformation, but the shortterm challenges are so numerous and tough that even apparently successful CIOs seldom accomplish much more than keeping the lights on.

But some do. Some executives are credited with transformational leadership, and some CIOs have accomplished digital transformation of their organisations, or even sectors [1,2]. For instance, in Cases on IT Leadership, Bjørn-Andersen [3] presented 16 cases, including some spectacular transformation successes, such as Maersk (shipping), Lego (toys) and NOVO (pharmaceutical). Researchers have identified two key success factors for digital transformation: competent strategic management and some specific capabilities of the acting CIO [2].

However, there are many unresolved questions about the role of the CIO in digital transformation. One of them is the role of the environments, such as the role of the transformation team, the vendors, the senior management and perhaps most importantly, the role of the entire focal organisation.

Our starting point is that digital transformation requires a transformational CIO, but a successful transformation is the result of a collective organisational effort, not the sole result of a heroic and charismatic CIO. Our research context is the Scandinavian workplace tradition, emphasising a broad and inclusive approach to organisational change. Our research questions are,

- What characterises leadership in the digital transformation?

- What does the Scandinavian workplace model add to the knowledge of digital transformation leadership?

To develop our argument, we draw on insights from transformational leadership, the Scandinavian workplace model and an in-depth study of a turbulent transformation at the SAS airline. Our contribution is that the Scandinavian workplace model adds two 
elements: deep engagement with employees and a coaching leadership style, ensuring that the process leverages the competence of highly-skilled employees.

\section{Relevant Research}

\subsection{Digital Transformation and the CIO}

Bharadway et al. [4] presented influential ideas on digital transformation. Their key point is that firms no longer need an IT strategy (as one of several sub-strategies) but rather a digital business strategy, defined as an organisational strategy formulated and executed by leveraging digital resources to create differential value. The digital business strategy is described as different than the IT strategy in four aspects: scope (transcends traditional functional silos), scale (rapid digital scale-up and down), speed (of product launches and decisions) and source of value creation (multi-sided business models and information). This also requires a different type of CIO.

In The Transformational CIO [2], Muller builds on established insights from strategic management for the transformational CIO:

- Define a vision: the people carrying out the transformation project must have a clear vision

- Build an executive team: this includes usually bringing in new managers and moving people to different positions

- Lead and inspire: this means to changing the IT organisation from a reactive to a proactive mode, and getting people to believe in your ideas

- Change the way people think and behave: the three essentials (people, business processes and technology) must be orchestrated together to accomplish the transformation

Muller points to the fact that most CIOs are not transformational, and that the successful CIO must be able to convince the business that the IT unit is a real business partner, with the necessary insight and means to transform the organisation.

A successful transformation is also context sensitive. In his classic HBR article [5], Kotter argued that most transformation efforts failed because in a normal business-asusual situation, there are simply too many forces that resist change. Only in a crisis are these forces are weakened, and a window of opportunity emerges, where real transformation is possible.

Which attributes, then, are important for the transformational CIO?

\subsection{Transformational Leadership}

Leadership is described as 'a stream of evolving interrelationships in which leaders are continuously evoking motivational responses from followers and modifying their behaviour as they meet responsiveness or resistance, in a ceaseless process of flow and counter flow' [6]. Masood et al. [7] argued that in a global and changing business world, leaders must be able to respond to continuous changes in markets, customer needs, resources and technologies. Consequently, transformational leadership, first introduced by Burns [6], has received a tremendous amount of attention and has emerged as one of the most dominant leadership theories [8]. The essence of transformational leadership, as postulated by Boehnke et al. [9], is that superior performance is possible only by transforming followers' values, attitudes and motives from a lower to a higher plane of arousal and maturity. Research by Krishnan [10] suggests that superior performance is possible only through stimulating and motivating followers to higher levels of performance through transformational leadership.

According to Bass [11], transformational leaders possess good visioning, rhetorical and impression management skills, and they use these skills to develop strong emotional bonds with followers. Transformational leaders offer a purpose that transcends short- 
term goals and focuses on higher-order intrinsic needs [6]. Four dimensions of transformational leadership have been proposed [8], [12]). Firstly, idealised influence characterises the extent to which a leader behaves in admirable ways that encourage followers to identify with him or her. Second, inspirational motivation describes the extent to which a leader puts forth a vision which is appealing and inspiring to followers. Third, intellectual stimulation characterises the extent to which a leader challenge existing assumptions and takes risks that stimulate and encourage creativity in followers. Finally, individual consideration describes the extent to which a leader listens to followers' concerns and seeks to meet their individual needs.

\subsection{The Scandinavian Workplace Model and Scandinavian Leadership}

The three Scandinavian countries (Sweden, Denmark and Norway) form a rather tight cluster $[13,14]$. They share a common history, their languages are similar, they share the same Lutheran religion, and politically, they share the social-democratic ideology responsible for what is known as 'the Scandinavian workplace model'. The Scandinavian model is a relatively loose term. At a macro level, the model refers to a highly educated and relatively homogeneous workforce, stable labour relations, a high level of unionisation, small wage differentials, high productivity and strong governments committed to an extensive welfare and social security system with full employment as an absolute objective [15], [16]. At a micro level, the term refers to a relatively high degree of workplace democracy based on co-operation, consensus, participation and power-sharing [15]. The classic survey by Hofstede [17] typifies a rather distinctive Scandinavian workplace culture, categorised as very low on power distance and with a preference for good working relations.

Research has revealed that leadership in Scandinavia differs in many ways from that of other supranational entities [15], and Scandinavian leadership is suggested as a distinctive management concept. Scandinavian leaders favour coaching rather than directing [18], frequently ask subordinates for opinions [19], are more willing to delegate decisions to subordinates than in many other nations [20] and tend to favour team integration and team collaboration [21].

\section{Method}

The chosen approach was engaged scholarship [22], defined as a form of inquiry where researchers involve practitioners and leverage their different perspectives to learn about a problem domain. The basic idea of engaged scholarship is that when researchers interact and learn with practitioners, it is more likely to produce significant knowledge advances than doing either basic or applied research. A key point is that any lack of agreement may provide particular illumination when addressing complex research questions. Engaged scholarship is based on a critical realist philosophy of science.

\subsection{Research Setting}

The setting was unusual. In 2013 a new CIO, Mr Aanby, was hired by the Scandinavian airline SAS, first to deal with an immediate crisis and later to transform the airline's IT structure and services. Aanby had previously been an IT manager at SAS but had spent the past decade as CIO and director of business development at SAS's main competitor Norwegian Air Shuttle. At Norwegian, Aanby had built a modern, SOA-type IT architecture and an agile IT organisation, which had been a key element in Norwegian's spectacular success [23] during the decade the start-up airline had grown to a billiondollar international airline, carrying 25 million passengers in 2015. In 2012 Aanby quit Norwegian and started a consulting business. Shortly after, SAS called on his services, asking him to do the same as he had accomplished in Norwegian, i.e. to establish a lowcost IT-platform to support business agility (or almost the same but from an opposite 
position). At Norwegian, the challenge had been to build a new solution from scratch; at SAS, the challenge was to reduce the complexity of a mature but siloed IT structure.

\subsection{Data Collection and Analysis}

In line with van de Ven's method for engaged scholarship [22], the study was conducted in co-operation with Aanby and with other key actors in SAS.

The main steps were:

(i) Ground problem/question in reality up close and from afar

$\mathrm{Mr}$ Aanby and the first researcher had co-researched the Norwegian case and copublished results [24]. Building on Aanby's experience in SAS, we wished to assess the digital transformation in SAS, with a particular focus on the role of the Scandinavian workplace model and Scandinavian leadership.

(ii) Develop alternative theories to address the question

In particular, we wished to investigate the environments of the transitional CIO, in order to theorise on which factors that might support digital transformation. Our assumption was that this aspect was central but under-researched.

(iii) Collect evidence to compare models or theories

A case description was crafted, building on in-depth interviews with seven key informants from the SAS case, and supplemented with written records, such as project documentation, technical descriptions and evaluations. The analysis focused on identifying specific patterns of the change process, in order to understand the transformational CIO and assess the Scandinavian contribution.

(iv) Communicate and apply findings to address the problem/question

Preliminary results were discussed with the key informants. The same applied to draft versions of this paper.

\section{The Case}

SAS is an international airline, based in Scandinavia, partly owned by the governments of Sweden, Denmark and Norway. Founded in 1946, the company operated relatively protected by privileged routes inside Scandinavia and regulated international connections. After the European airlines were deregulated in 2000, competition became much stronger; air ticket prices fell, and SAS revenues plummeted. The company were used to being rich and protected, and struggled to adjust the new situation. Although SAS had been losing money since 2002, the sense of crisis was weak, and programmes and projects had continued. Instead of a turnaround strategy and operations, the company chose to solve the problems financially, by selling assets and by asking for more money from government shareholders.

\subsection{An International Airline in Crisis in 2012}

By November 2012, the crisis became acute because the company was running out of cash and not paying its bills. One of the actions was a short-term engagement of HansPetter Aanby, a former SAS IT executive who later had built a strong career as the CIO of SAS's main competitor, Norwegian Air Shuttle. Aanby had recently quit Norwegian and was available as a consultant. His assignment was to ensure - in the case of SAS bankruptcy - that the IT systems would be in operation to allow aircraft from various destinations across the globe to return to Scandinavia.

By the end of December, the crisis had been temporarily solved by SAS's creditors, the banks, which granted the necessary cash. In practice, this meant that the banks were taking the main decisions during the coming period. The key short-term decision was to cut cost dramatically, and IT was not excluded; building on a report from PwC, the stated objective was to cut IT costs by $50 \%$ and IT personnel by $70 \%$, without negative effects on operations. Aanby was asked to take the CIO position and accepted. 
An overview of the chronology of the case is offered in Fig. 1.

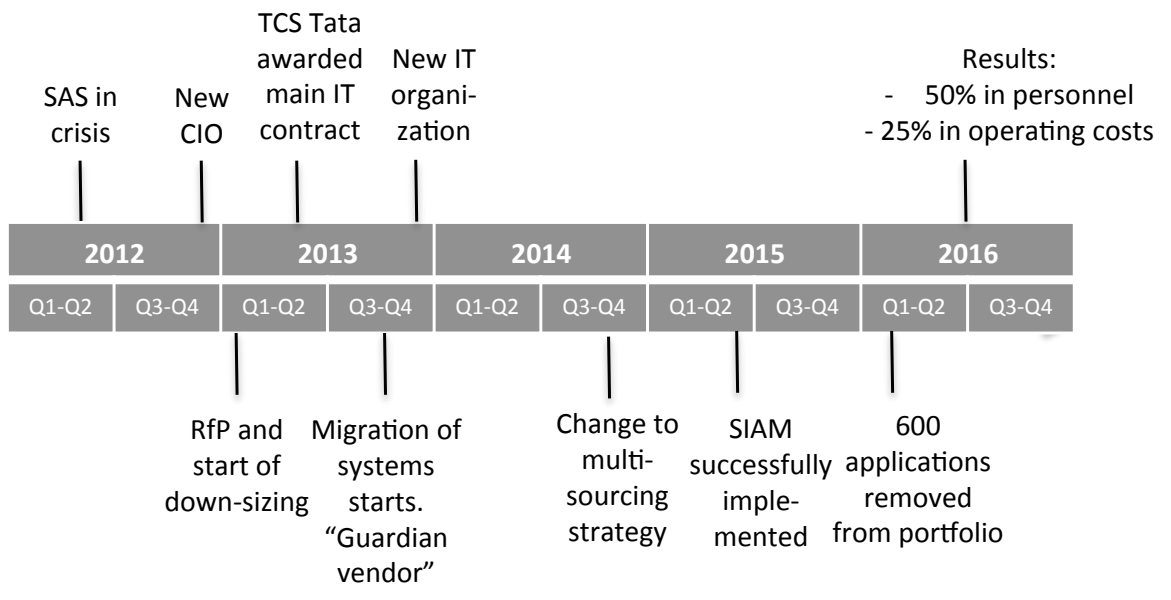

Fig. 1. Timeline.

\subsection{A New CIO in 2013}

Reducing IT costs by $50 \%$ (of an official budget of 1.3 billion SEK, which in reality turned out to be 1.7 billion) without affecting operations was extremely challenging. However, the IT function had not been well managed the past ten years, and there was some slack in several layers of the organisation. Aanby quickly initiated three initiatives, which were run in parallel:

- $\quad$ Establishing a new IT organisation and redesigning internal processes

- $\quad$ Reducing the number of systems and redesigning the IT architecture

- Negotiating and implementing a new sourcing model

\subsection{Establishing a New IT Organisation and Redesigning Internal Processes}

The new IT organisation was established with seven units as shown in Fig. 2. All managers (five of them called "business CIO"), with one exception, were new; most of them came from other companies.

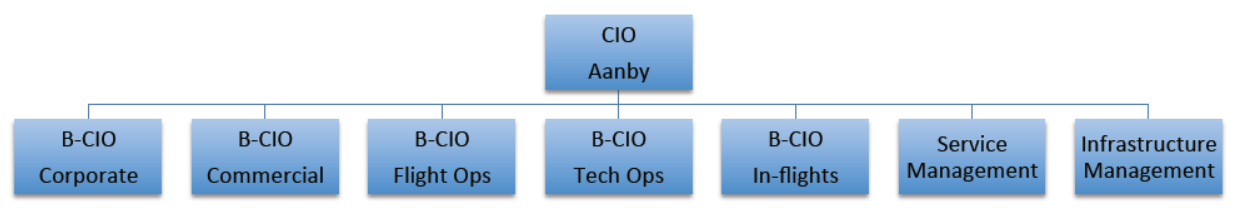

Fig. 2. The new IT organisation.

The business CIOs were given extensive decision rights. One commented:

I spent my first month learning the business, and meeting as many stakeholders as possible, business managers, IT personnel, vendors and customers. I did not start with the existing IT resources, but began by trying to understand what was really important for our internal and external customers. Then I proceeded by designing how the business processes should work with IT and asking how we could deliver the services at much lower costs.

Over time, SAS had developed a high diversity of business processes and IT systems. In 2013, although development and operations had been outsourced, the IT staff included 211 personnel. The goal was to reduce this number to 60. Many IT employees 
were assigned to departmental systems. When many of these systems were terminated, the consequence was usually lay-offs. This process is regulated extensively in Swedish law and was carefully executed. The CIO commented:

Around any IT system, over time, a small ecology of owners, users, hardware and tools, developers and operation support, develops. So, reducing the number of business processes and systems also meant staff reduction. We dealt with this very carefully, involving the unions in every step. It took time and effort, but we found reasonable solutions with relatively low levels of conflict.

\title{
4.4 Reducing the Number of Systems and Redesigning the IT Architecture
}

The systems portfolio in SAS had grown since the early 1970 s, and by 2013 , it included around registered 1200 applications, large and small, which were run by CSC in the Copenhagen data centre. The average system age was 15-20 years. Some of them were central business systems in air planning and operations, marketing, booking and financials, and were crucial to the company. However, most applications were departmental solutions serving a useful purpose, but not all were really necessary. But which ones could be removed? Aanby and his management team had the advantage of deep knowledge of the business and IT sides of the matter and did not leave the decision to middle management. Instead, they went head-on, analysed every application and decided its importance: Was it really needed? Could other applications provide the same or equal functionality? Through this process, they decided that approximately $50 \%$ of the 1200 applications could be discarded.

The remaining applications needed better integration. The IT architecture was partly built on an enterprise bus solution (Tibco), and Aanby decided to keep this as the backbone. The major business systems were first integrated and later worked as a gravitational force on other applications. A service-oriented approach was chosen, where integrations were analysed, and in many cases rebuilt as services. Gradually, a more integrated and leaner portfolio emerged, and by 2015, the number of applications was reduced to 600 , in 175 systems.

In parallel, the core systems were gradually renewed; in 2014 a new SAP platform and an e-commerce solution were implemented, and in 2015 new solutions for revenue management and aircraft maintenance were introduced. The speed of change was considerable; in the period 2013-15 there were 238 new releases, i.e. more than one every week. There were no major disruptions of IT stability during the transformation period. One business CIO commented:

\begin{abstract}
We worked extremely hard in this period, to keep operations going whilst changing the whole infrastructure. First we had to define a new configuration; then roll it out at all bases. We established a command centre, where managers, IT staff, vendors and business people met and solved problems. Up to 50 people attended these sessions, where decisions were taken on the go. We had to co-ordinate the actions of support personnel and technicians at a large number of airports around the world, and the same time deal with technical and vendor issues.
\end{abstract}

\subsection{Negotiating and Implementing a New Sourcing Model}

IT development and operations had been outsourced to CSC in 2004, with the data centre in Copenhagen and development in Stockholm. The contract was expensive and the services unsatisfactory, and in February 2013 Aanby issued a Request for Proposal. The main contract was awarded to Tata Consultancy Services (TCS), an Indian IT service giant, at a much lower cost. Transitioning to a new data centre in Aarhus, from CSC to Tata, was complicated and ripe with conflicts. Each system was analysed in terms of services and dependencies, and then changed, moved and tested, before set into production. One manager commented: 
We realised from the start that we were not only changing the technology, but more importantly, changing the company's business processes. Our key challenge was to deliver better services to customers, at lower costs. In order to do this, we had to understand the inside of the processes, both the people and the technology. This could not be done in contracts; rather we had to work very closely with the vendors to design the right solutions. Even the CIO was very hands-on with these details.

Infrastructure was completely renewed; 4000 servers, 15.000 workstations, and various LAN/WAN networks were installed. In addition to Tata, large contracts were awarded to Amadeus, SITA and others; in total 300 IT vendors (many of which were local companies delivering services to airports around the world) were involved.

\subsection{Moving from Guardian Vendor to SIAM in 2014}

When Tata was implementing the new solution in autumn 2013, they assumed the role of guardian vendor, i.e. ensuring that all sub-vendors delivered according to contracts and Service Level Agreements. This arrangement turned out to be unsuccessful; it led to a number of conflicts, vendor responses to problems took a long time, and SAS lacked direct access to information on upcoming issues.

The solution was a different model, called Service Integration and Management (SIAM), which is a management approach to dealing with multi-sourcing [25]. Multisourcing deals with a blend of internal and external services, and offers the opportunity to select best-of-breed services from various vendors. The challenge is to integrate these, often interdependent, services into a seamless whole.

SAS decided in autumn 2014 to implement SIAM, and this element was taken out of the contract with Tata. The transition was demanding, because it involved technical redesign and new contracts with vendors, as well as orchestrating the services to the SAS organisation. Firstly, an ITIL consultant was hired to help structure the new SIAM process. Secondly, an internal unit was established to take responsibility for integration and services. In March 2015, the SIAM solution was working successfully; the incident and problem management processes were in place, users were satisfied, and vendor issues were dealt with at operational level. See Fig. 3.

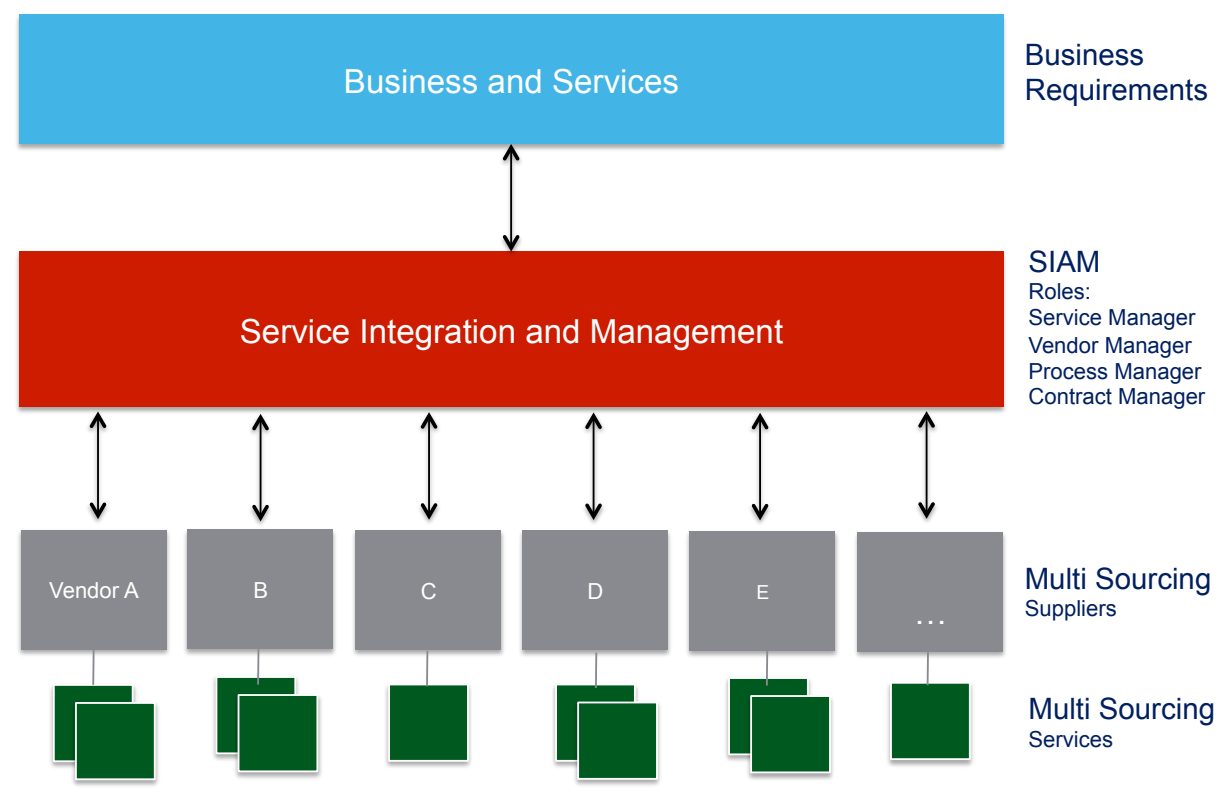

Fig. 3. Multi-sourcing with service integration and management.

As illustrated in Fig. 2, the SIAM unit integrated the services from the various vendors and served as a facade to the business. 


\subsection{CIO Leadership}

Mr Aanby turned out to be a very hands-on leader but also kept the vision clear. One of his business CIOs described his leadership in these terms:

He was quite likeable, always in a good mood, joking and laughing. But he was very clear on the overall goals, and on the gravity of the situation. He explained in several large briefings what the mission was, and how we should deal with it. In negotiations, both with vendors and the unions, he was tough. It was evident that he knew what he was doing, and we knew he had the necessary experience. He was not hiding behind polished consulting language but used funny illustrations and stories to illustrate his thinking.

The overall focus was on changing the company's business processes. The restructuring of the processes was the responsibility of his "business CIOs", who were all quite experienced in this line of thinking. Restructuring often implied simplifying or automating sub-processes, in order to provide better services and reduce costs. For instance, marketing and sales processes were fragmented in different units and IT systems, and the new solutions were simpler and more efficient. Aanby had the advantage of extensive experience with the strategic and commercial issues, as well as the technical issues. A business CIO commented:

He was very hands-on, knowing the critical details. For instance, if a middle manager argued that there were specific reasons for keeping things as they were, Aanby knew the details so well that he could intervene, and argue - correctly - that the business process should be changed, and describe why this was possible. Without this ability, we would have accomplished much less.

\subsection{Results in 2016}

By summer 2016, the transformation project had been completed, and the CIO left. The results were impressive; IT personnel had been reduced by $50 \%$, and operative costs had been reduced by $25 \%$. SAS had new and much more flexible solutions, and operations had been running smoothly during the whole transition.

However, this also meant that the objectives had not been fully reached. One reason was that new solutions had been added along the way, increasing available services but also costs. Another reason was that some old applications in the operative part were not changed, because of the operative risk. A third was that the initial cost was set too low; the total IT costs amounted to 1.7 billion SEK, not 1.3 billion.

\section{Discussion}

Considering the case, we think it is reasonable to conclude that it confirms the main assumptions of the strategic management and digital strategy. It was the sense of urgency and crisis that made the transformation possible [5], and the change from IT strategy to digital business strategy [4] is reflected in the depth of the transformation. In addition, the action pattern of the transformational CIO is in line with the research, for instance the need for strong senior management support. One top executive in SAS commented:

Remember, a CIO can do only as much as the organisation allows him. In this kind of transformation, there are many forces that resist change. If not overridden by top management, they will obstruct the $\mathrm{CIO}$; there are potentially an endless number of reasons to keep things as they are.

Regarding the personal attributes of the transformational CIO, this is a complex topic, but we believe that the leadership of Mr Aanby resonates with earlier research [8], [12], as shown in Table 1. 
Table 1. Characteristics of the transformational leader.

\begin{tabular}{ll}
\hline Aspect & How the SAS CIO enacted this aspect \\
\hline Idealised influence & $\begin{array}{l}\text { The CIO established trust through open and truthful } \\
\text { communication }\end{array}$ \\
Inspirational motivation & $\begin{array}{l}\text { He put forth a clear mission and stayed with it, also in times of } \\
\text { crisis }\end{array}$ \\
Intellectual stimulation & $\begin{array}{l}\text { He worked with high risk throughout the process, and inspired } \\
\text { and empowered his colleagues to find solutions }\end{array}$ \\
Individual consideration & $\begin{array}{l}\text { He dealt individually with his managers and employees, } \\
\text { empowering the able }\end{array}$ \\
\hline
\end{tabular}

This certainly does not mean that all employees appreciated the CIO's leadership. The transformation was quite turbulent, and some employees may have interpreted the CIO's behaviour not as good leadership but rather as a kind of soft manipulation to make people work extremely hard over a long period of time. It might have some significance that the importance of involving different people, with divergent perspectives, in multiple aspects of the research process, in order to create a richer process that can enable the complexity of important problems to be examined more fully.

Mr Aanby chose to leave his position when the mission had been completed.

There is, however, one aspect that needs more discussion, namely the role of the environment and organisation in the transformations process. We will assess this in the following section, focusing on two issues of the digital transformation: the Scandinavian model for engagement and leadership.

\subsection{The Scandinavian Approach I: Deep Participation}

Whilst the CIO literature [2] and the transformational leadership research [8] emphasise the need for good communication, stakeholder relationships and stimulated and motivated followers, the SAS case goes beyond this in its continuous and deep engagement with employees.

The level of engagement was deep in the SAS case, and we can describe it on three levels. Firstly, at the top level the goals of the initiative (which were dramatic) were discussed with the trade unions (of which SAS had a large number), and an agreement on the change process was reached, which was extensively communicated. Secondly, the need for each system was assessed, and in the many cases of system termination, employees were deemed redundant. Each case was negotiated with the employee and his union, and flexible solutions were found. Thirdly, during the change process, managers (including Aanby himself) were heavily engaged, taking the time to listen, discuss and decide. One of the managers commented:

Big changes require an understanding of the key issues from all stakeholders, and we spent time on this. It is much easier to conduct a transformation like this when employees are involved. We also spent some time explaining our foreign partners this; they clearly were not used to this kind of time-consuming process.

The Scandinavian approach to leadership recognises that transformation processes cannot be run solely top-down but are subject to negotiation and sharing of burdens and benefits. Research has shown that non-Scandinavian managers believe that this leads to slow and ineffective decision-making, whilst Scandinavian managers argue that the stronger commitment is more important [26].

\subsection{The Scandinavian Approach II: Knowledge-Sharing}

The deep level of engagement was important not only for employee commitment but also for knowledge-sharing. Research has shown that Scandinavians prefer leadership based on coaching, rather than direction [18], and the use of objectives and values, not 
to command and control [15]. This requires that employees are empowered with some space for autonomy, but also that knowledge workers engage heavily in problem solving.

Both of these conditions were present in the SAS case. The transformation included almost every business process and unit in the corporation, and every detail had to be right. This depended to a large degree on employees' local knowledge, and the change process (and culture) allowed for open discussions on these issues. One of the business CIOs commented:

An important reason for the success was the leadership style. First, the managers were very relaxed in terms of authority, allowing employees to take decisions when needed, which was extremely important in a project like this. Second, we were able to leverage the competence of involved employees, since everybody were encouraged to express their opinion at meeting. In a more hierarchical culture, this seldom happens, because only the boss will speak.

Summing-up the Scandinavian contribution:

One of the key insights of Scandinavian leadership is that commitment requires meaningful and real engagement, and that the leadership style leverages the knowledge of employees. Both of these aspects were success factors in the SAS case.

\section{Conclusion}

In this paper, we analysed a digital transformation process in an international airline, in order to understand the role of the CIO. The research questions were (i) what characterises leadership in the digital transformation, and (ii) what does the Scandinavian workplace model add to the knowledge of digital transformation leadership?

We find that the insights from extant research are valid also for Scandinavian transformation initiatives. However, we add to the knowledge of digital transformation two key elements from the Scandinavian workplace model; deep employee participation, and a leadership culture that leverages employee knowledge.

\section{Acknowledgements}

We thank the informants for their time and engagement.

\section{References}

1. Hess, T., Matt, C., Wiesböck, F., Benlian, A.: Options for Formulating a Digital Transformation Strategy. MIS Q. Exec. 15, 103-119 (2016)

2. Hoehle, H., Venkatesh, V.: Mobile Application Usability: Conceptualization and Instrument Development. MIS Q. 39, 435-472 (2015)

3. Hansen, M.T.: The Search-Transfer Problem: The Role of Weak Ties in Sharing Knowledge Across Organization Subunits. Adm. Sci. Q., 44, 82-111 (1999)

4. Turkulainen, V., Aaltonen, K., Lohikoski, P.: Managing Project Stakeholder Communication: The Qstock Festival Case. Proj. Manag. J., 46, 74-91 (2015)

5. Thomas, M., Jacques, P.H., Adams, J.R., Kihneman-Wooten, J.: Developing an Effective Project: Planning and Team Building Combined. Proj. Manag. J., 39, 105-113 (2008)

6. Manu, E., Ankrah, N., Chinyio, E., Proverbs, D.: Trust Influencing Factors in Main Contractor and Subcontractor Relationships During Projects. Inter. J. Proj. Manag., 33, 1495-1508 (2015)

7. Buvik, M.P., Rolfsen, M.: Prior Ties and Trust Development in Project Teams - A Case Study from the Construction Industry. Inter. J. Proj. Manag., 33, 1484-1494 (2015)

8. Pee, L.G., Kankanhalli, A., Kim, H.-W.: Knowledge Sharing in Information Systems Development: A Social Interdependence Perspective. J. Assoc. Info. Syst., 11, 550 (2010)

9. Nooteboom, B., Van Haverbeke, W., Duysters, G., Gilsing, V., van den Oord, A.: Optimal Cognitive Distance and Absorptive Capacity. Res. Policy, 36, 1016-1034 (2007)

10. Lee, L., Reinicke, B., Sarkar, R., Anderson, R.: Learning Through Interactions: Improving Project Management Through Communities of Practice. Proj. Manag. J., 46, 40-52 (2015)

11. Mueller, J.: Formal and Informal Practices of Knowledge Sharing Between Project Teams and Enacted Cultural Characteristics. Proj. Manag. J., 46, 53-68 (2015) 
12. Solli-Sæther, H., Karlsen, J.T., van Oorschot, K.: Strategic and Cultural Misalignment: Knowledge Sharing Barriers in Project Networks. Proj. Manag. J., 46, 49-60 (2015)

13. Ronen, S., Shenkar, O.: Clustering Countries on Attitudinal Dimensions: A Review and Synthesis. Acad. Manag. Rev., 10, 435-454 (1985)

14. Hoppe, M.H.: The Effects of National Culture on the Theory and Practice of Managing R\&D Professionals Abroad. R\&D Manag., 23, 313-325 (1993)

15. McLeod, L., Doolin, B.: Information Systems Development as Situated Socio-Technical Change: A Process Approach. Eur. J. Info. Syst., 21, 176-191 (2012)

16. Ghobadi, S., Mathiassen, L.: Perceived Barriers to Effective Knowledge Sharing in Agile Software Teams. Info. Syst. J., 26, 95-125 (2016)

17. Hofstede, G.: Culture's Consequences. Sage, Beverly Hills (1980)

18. Zander, L.: The Licence to Lead, An 18-Country Study of the Relationship Between Employees' Preferences Regarding Interpersonal Leadership and National Culture. In: Institute of International Business, Stockholm School of Economics, Stockholm (1997)

19. Avison, D., Malaurent, J.: Qualitative Research in Three IS Journals: Unequal Emphasis but Common Rigour, Depth and Richness. Syst. d'info. Manag., 18, 75-123 (2013)

20. Kim, G., Behr, K., Spafford, G.: The Phoenix Project: A Novel About IT, DevOps, and Helping Your Business Win. IT Revolution, Portland, Oregon (2014)

21. Bass, L., Weber, I., Zhu, L.: DevOps: A Software Architect's Perspective. Addison-Wesley Professional, New York (2015)

22. Amabile, T.M., Conti, R., Coon, H., Lazenby, J., Herron, M.: Assessing the Work Environment for Creativity. Acad. Manag. J., 39, 1154-1184 (1996)

23. Henfridsson, O., Bygstad, B.: The Generative Mechanisms of Digital Infrastructure Evolution. MIS Q., 37, 907-931 (2013)

24. Bygstad, B., Aanby, H.P.: ICT Infrastructure for Innovation: A Case Study of the Enterprise Service Bus Approach. Info. Syst. Frontiers, 12, 257-265 (2010)

25. Dibrell, C., Davis, P.S., Craig, J.: Fueling Innovation Through Information Technology in SMEs. J. Small Bus. Manag. 46, 203-218 (2008)

26. Das, S.R., Zahra, S.A., Warkentin, M.E.: Integrating the Content and Process of Strategic MIS Planning with Competitive Strategy. Dec. Sci. 22, 953-984 (1991) 